\title{
Psychological medicine and the future of psychiatry
}

\author{
Michael Sharpe
}

\section{Summary}

Psychological medicine (liaison psychiatry) aims to integrate psychiatry into other areas of medicine. It is currently enjoying considerable expansion. The degree to which it can take advantage of this opportunity will be important not only for its own future, but also for the survival of psychiatry as a medical discipline.

\section{Declaration of interest}

M.S has worked with various National Health Service bodies to develop clinical services, research and teaching

in psychological medicine.
Professor Michael Sharpe is Professor of Psychological Medicine at the University of Oxford, UK.

\section{What is psychological medicine?}

Liaison psychiatry is the subspecialty of general psychiatry that is concerned with the management of psychiatric illness in general medical settings. Because this work is becoming more about the integration of psychiatry into medicine than about merely liaising (linking) with it, and also increasingly involves disciplines other than psychiatry, such services are often called departments of psychological medicine, a term which may eventually replace liaison psychiatry as a name for the subspecialty. ${ }^{1}$

\section{History}

Historically, physicians working in general hospitals treated patients with all kinds of illnesses. By the late 1800s however, psychiatry was established as a specialty developed for the care of the 'mentally ill' and it became increasingly separate from the rest of medicine. Although the next 100 years saw spectacular advances in the understanding of the mechanisms and consequently in the diagnosis and treatment of physical disease, the understanding of mental illness seemed to have lagged behind. However, this apparent failure of psychiatry has had the advantage of allowing it to retain its strengths in humane social and psychological care, key aspects of clinical practice that an increasingly technological 'physical' medicine has arguably lost.

Liaison psychiatry aims to put these skills back into medical care. Its origins were in the increasing recognition of the limitations of 'physical' medicine, which led to psychiatrists being asked to help with patients whose problems were considered to be 'mental'. The psychiatrist's visits to general hospitals were mostly to assess patients who were obviously psychotic, had self-harmed or manifested disturbed behaviour, and the anticipated outcome was often rapid transfer away from the medical ward to a mental hospital. But as time passed there was a trend to greater integration. Small psychiatry departments became established within many general hospitals and the resulting greater interaction between psychiatrists and physicians led to a much wider range of referrals being made. These included patients who appeared depressed or anxious, patients with physical symptoms that defied explanation as manifestations of organic disease and patients who did not adhere to their prescribed medical treatment. Development was slow and formal recognition of liaison psychiatry by the Royal College of Psychiatrists as a subspecialty was only achieved as recently as 1997.

\section{Recent developments}

These early developments were largely opportunistic, being driven more by relationships between individuals than by formal planning. The result is a huge variation in current service provision in the UK: some hospitals have large multidisciplinary services; others have nothing more than a visiting community psychiatrist. ${ }^{2}$ In the past few years, however, there has been a step change in thinking about this area of psychiatry. There are several reasons.

First, there is now almost overwhelming evidence of a clinical need. The average age of general medical in-patients is now well over 65 years and disorders such as delirium and dementia have become too prevalent and visible to be ignored. ${ }^{3}$ This need has been underscored by the Francis Report into failures of care for such patients at a Mid Staffordshire hospital. ${ }^{4}$

Second, there is a growing quantity of research evidence which indicates that better management of psychiatric illness in medical patients can achieve the 'Holy Grail' of improved outcomes at lower cost. One widely quoted example of this is the report on the Rapid Assessment Interface and Discharge (RAID) project at City Hospital, Birmingham. A before-and-after study of this intensive psychological medicine service reported considerable savings, mostly by reducing the bed days taken up by frail elderly patients. ${ }^{5}$ Research has also highlighted other areas where psychological medicine services could achieve better outcomes at lower cost, including medically unexplained somatic symptoms ${ }^{6}$ and depression comorbid with chronic medical illness.

Third, there is a growing demand from both clinicians and patients for more integrated and patient-centred care. The benefits of such integration of psychiatry into other areas of medicine for both the patient's experience of medical care and clinical outcomes are starting to be confirmed by research. ${ }^{8}$

Multiple reports have recognised these drivers and have recommended the systematic and planned expansion of psychological medicine., ${ }^{2,9-12}$ This has resulted in the commissioning of new services, specifically designed to address these needs by responding rapidly to referrals, providing practical assistance with all types of psychiatric problems in patients of all ages (including the elderly), and providing systematic training and support in psychiatric aspects of care to the medical and nursing staff. 


\section{The seven challenges}

The pace of change is rapid. But will it continue? I suggest that there are seven challenges that must be addressed if psychological medicine is to continue its current development.

First, psychological medicine services must develop greater clarity about what they are seeking to achieve. Although meeting 'unmet psychiatric need' by seeing referrals may seem sufficient, a more precise articulation of the service aims is required. These aims are likely to fall into four main domains:

(a) improving the psychiatric and medical outcomes of patients;

(b) enhancing the patient's experience of medical care;

(c) ensuring patient safety;

(d) contributing to the greater overall cost-effectiveness of medical services. $^{2}$

Data derived from the measurement of these outcomes need to become routinely available.

Second, if psychological medicine services are to achieve these aims, they must beware of excessive subspecialisation: we already have neuropsychiatry, perinatal psychiatry, transplant psychiatry, adult liaison, old age liaison and child liaison psychiatry. Although specialisation might be considered a welcome development in a growing specialty, clinical teams are likely to have a more sustainable and greater impact if they retain a commitment to flexible and shared service provision. Arguably, these separate small subspecialties would achieve more by joining forces under a single banner.

Third, there needs to be greater creativity in organising and managing service provision. The traditional mental health trust-run service offers the advantage of a clear link with other areas of mental health provision, but offers less engagement with general hospital colleagues. An acute medical trust-run service offers more integrated care, closer alignment of practice and a greater opportunity to influence the general hospital culture but at the risk of potential isolation from the rest of psychiatry. ${ }^{13}$ Consequently, models of provision that cross traditional trust boundaries need to be developed.

Fourth, psychological medicine can increase its reach by working with those professions and specialties that also provide a supplement to disease-focused medical care. These include not only psychology and nursing, but also pain and palliative medicine services. Although these clinical specialties each have their own history and identity, there is a strong case for better coordination of their efforts, and perhaps even for their integration.

Fifth, psychological medicine must expand beyond the general hospital. Although general hospitals need these services more than ever before, there is also an increasing need to move into the community and to support primary care. Indeed, one of the most important developments in the USA has been the collaborative care model, in which psychiatrists lead teams that work together with primary care physicians to improve the management of psychiatric illness comorbid with chronic medical conditions. ${ }^{7}$

Sixth, sustainable mechanisms of funding must be identified. This is especially topical as neither of the current approaches for commissioning mental or physical care is suitable for the funding of psychological medicine services. It seems likely that a combination of central commissioning for specialist services, local commissioning as part of each medical service specification and funding by trusts themselves for the added value psychological medicine provides, will be needed.
Finally, we urgently need more and better research to inform and evaluate innovative interventions and models of delivering psychological medicine services. The current evidence base is modest and most of it is from the USA. Better and larger clinical trials done in a UK setting are essential.

\section{Conclusions}

Psychiatry has become separate from the rest of medicine. From small beginnings liaison psychiatry is leading its reintegration. This reintegration of psychiatry provides a 'win-win' opportunity: for medicine, it offers to make up for the deficits consequent on an excessive focus on physical disease. It also has the potential to improve the experience, safety, outcomes and cost-effectiveness of medical care. For psychiatry, it offers the opportunity to confirm that psychiatrists are doctors; doctors with important skills that have much to offer general healthcare in the 21st century. The recognition of this fact is important in ensuring parity of esteem with other areas of medicine and improving recruitment into the specialty. The success of psychological medicine in taking advantage of the opportunities it has been given will be important, not only to the subspecialty, but to the survival of psychiatry as a medical discipline.

Correspondence: Michael Sharpe, MA, MD, FRCP, FRCPsych, Professor of Psychological Medicine, University of Oxford Department of Psychiatry, Warneford Hospital, Oxford OX3 7JX, UK. Email: michael.sharpe@psych.ox.ac.uk

First received 7 Jun 2013, final revision 21 Oct 2013, accepted 6 Nov 2013

\section{References}

1 Lloyd GG, Mayou RA. Liaison psychiatry or psychological medicine? Br J Psychiatry 2003; 183: 5-7.

2 Parsonage M, Fossey M, Tutty C. Liaison Psychiatry in the Modern NHS Centre for Mental Health, 2012.

3 Royal College of Psychiatrists. Who Cares Wins: Improving the Outcome for Older People Admitted to the General Hospital. Royal College of Psychiatrists, 2005.

4 Francis R. Report of the Mid Staffordshire NHS Foundation Trust Public Inquiry. TSO (The Stationery Office), 2013.

5 Parsonage M, Fossey M. Economic Evaluation of a Liaison Psychiatry Service. Centre for Mental Health, 2011.

6 Bermingham SL, Cohen A, Hague J, Parsonage M. The cost of somatisation among the working-age population in England for the year 2008-2009. Ment Health Fam Med 2010; 7: 71-84.

7 Katon WJ, Lin EH, Von Korff M, Ciechanowski P, Ludman EJ, Young B, et al. Collaborative care for patients with depression and chronic illnesses. $N$ Engl J Med 2010; 363: 2611-20.

8 Strong V, Waters R, Hibberd C, Murray G, Wall L, Walker J, et al. Management of depression for people with cancer (SMaRT oncology 1): a randomised trial. Lancet 2008; 372: 40-8.

9 Mental Health Network. Healthy Mind, Healthy Body: How Liaison Psychiatry Services can Transform Quality and Productivity in Acute Settings (Briefing, Issue 179). NHS Confederation, 2009.

10 Naylor C, Parsonage M, McDaid D, Knapp M, Fossey M, Galea A. Long-Term Conditions and Mental Health. King's Fund, 2012.

11 Department of Health. No Health Without Mental Health: Implementation Framework. HM Government, 2012.

12 Academy of Medical Royal Colleges. No Health Without Mental health: The Alert Summary Report. Academy of Medical Royal Colleges, 2009.

13 Joint Commissioning Panel for Mental Health. Guidance for Commissioners of Liaison Mental Health Services to Acute Hospitals. JCPMH, 2013. 